\title{
Publisher Correction: Dynamics for El Niño-La Niña asymmetry constrain equatorial-Pacific warming pattern
}

\author{
Michiya Hayashi, Fei-Fei Jin \& Malte F. Stuecker (1)
}

Correction to: Nature Communications https://doi.org/10.1038/s41467-020-17983-y, published online 28 August 2020.

The original version of this Article contained errors in the author affiliations.

Affiliations 1 and 2 incorrectly read 'Department of Atmospheric Sciences, SOEST, University of Hawaiian 'Okina at Mānoa, 2525 Correa Rd., Honolulu, HI 96822, USA' and 'Department of Oceanography and International Pacific Research Center, SOEST, University of Hawaiian 'Okina at Mānoa, 1680 East-West Rd., Honolulu, HI 96822, USA' instead of the correct 'Department of Atmospheric Sciences, SOEST, University of Hawai'i at Mānoa, 2525 Correa Rd., Honolulu, HI 96822, USA' and 'Department of Oceanography and International Pacific Research Center, SOEST, University of Hawai'i at Mānoa, 1680 East-West Rd., Honolulu, HI 96822, USA.'

This has now been corrected in both the PDF and HTML versions of the Article.

Published online: 11 September 2020

\footnotetext{
(c) Open Access This article is licensed under a Creative Commons Attribution 4.0 International License, which permits use, sharing, adaptation, distribution and reproduction in any medium or format, as long as you give appropriate credit to the original author(s) and the source, provide a link to the Creative Commons license, and indicate if changes were made. The images or other third party material in this article are included in the article's Creative Commons license, unless indicated otherwise in a credit line to the material. If material is not included in the article's Creative Commons license and your intended use is not permitted by statutory regulation or exceeds the permitted use, you will need to obtain permission directly from the copyright holder. To view a copy of this license, visit http://creativecommons.org/licenses/by/4.0/.
}

(C) The Author(s) 2020 